\title{
Transaction Costs and the Employment Contract in the US Economy*
}

\section{W. Bentley MacLeod** and Daniel Parent***}

October 26, 2012

This version: November 28, 2013

\begin{tabular}{|c|c|}
\hline Columbia University** & HEC Montreal*** \\
\hline Department of Economics & 3000, ch. de la Côte-Sainte-Catherine \\
\hline 420 West 118th Street & Montréal (Québec) \\
\hline New York, NY 10027-7296 & Canada H3T 2A7 \\
\hline bentley.macleod@columbia.edu & daniel.parent@hec.ca. \\
\hline
\end{tabular}

*The authors would like to thank Thomas Hubbard, Paul Oyer, Pablo Spiller, the anonymous referees and the other participants at the Conference in Honor of Oliver E. Williamson. Xing Xia provided excellent research assistance. We are responsible for all remaining errors. 


\begin{abstract}
The purpose of this paper is to use transaction cost economics (as in Williamson, Wachter and Harris (1979) and Williamson (1981)) to explore the relationship between job characteristics and observed employment contracts. Transaction cost considerations lead to jobs characterized by either normal or complex exchange. This in turn implies two contracting modes: contingent pay (fixed wage or piece rate/commission contract) or non-contingent pay (salary with possibly a bonus). We show empirically that observed job characteristics, as measured by the Dictionary of Occupational Titles (DOT), can explain the contract form observed in the Panel Study on Income Dynamics (PSID). Second, we discuss the implications of contract form for wages and mobility, and show that noncontingent pay jobs have more able workers in more durable relationships.
\end{abstract}

\title{
1 Introduction
}

In this paper we explore the extent to which transaction cost considerations can help explain features of the employment contract for a broad sample of workers in the United States, and the impact that compensation form has upon earnings and employment. The goal is to extend the standard model that focuses upon wage and employment dynamics, to one that integrates transaction costs. This approach, advocated by Williamson (1981), explains contract form in terms of relation-specific investment, the frequency of exchange, and the degree of uncertainty. In this paper we provide a formal model of these transaction costs for a repeated employment relationship, and show how they jointly help determine contract form.

Much of the research on employee compensation, beginning with Taylor (1911), focuses upon the question of how to efficiently compensate a worker as a function of observed worker characteristics, rather than job characteristics. Taylor observed 
that many workers would be willing to work harder for higher wages, and that the firm would gladly pay for this additional effort. This is the classic incentive problem. Beginning with Lazear (1986)'s work, Brown (1990) and Lazear (2000) have explored the effect that incentive pay has upon the selection of workers into jobs. In jobs that benefit from more effort, offering performance pay firms attract better quality workers, and generates a positive relationship between incentive pay, earnings and observed performance.

When workers are risk averse, then they would like to have more stable compensation. But if performance is observed with noise, then firms face a trade-off between providing insurance and incentives (see for example Ross (1973) and Holmström (1979)). When performance is multi-dimensional, then firms may not compensate some measures of performance due to the externality that would have upon other dimensions of a worker's performance (Holmström and Milgrom (1991)). Second, when there are fluctuations in a worker's outside option then this may also undo efforts to provide stable wages combined with incentives. If promised wages are too high then firms may choose to lay off the worker. Conversely, if there are low productivity realizations then there may be inefficient quits. Grossman and Hart (1981) use this observation to provide a theory of involuntary unemployment. Weitzman (1985) argues that this problem might be solved via profit sharing. Oyer (2004) shows that stock option plans can play the role of profit sharing, and lead to more stable relationships in practice. Lemieux et al. (2012) look at the impact that individual performance pay has upon job security, and show that employment is more stable at firms that use performance pay.

This work highlights the importance of variable pay to improve match quality when there is variation in worker characteristics. ${ }^{1}$ However, it is not successful in explaining all the variation in the data. Brown (1990), building upon Lazear (1986)'s 
model, explores the choice of contract form as a function of monitoring costs and the gains from matching pay more closely to performance. He finds that more complex jobs using a variety of tasks are less likely to use performance pay, and that larger firms rely more on fixed wage contracts. Brown (1992) extends this work to explore more closely the determinants of merit pay - pay that varies with supervisor reports. In this case the theory predicts that merit pay contracts should be associated with higher pay than fixed wage contracts because they should attract better workers. However, he finds no support for this result and concludes that this is an open question.

In this paper we provide a resolution to this problem using Williamson (1981)'s distinction between "hard contracting" (or black-letter law) for normal goods and services, and "soft contracting" for complex exchange ${ }^{2}$. Under "hard contracting" the contract or agreement specifies clear obligations for which a supply breach would lead to contract damages. MacLeod (2007) explicitly links the characteristics of the good to be exchanged (as opposed to the characteristics of the contracting parties) to the choice of contract mode. In this paper we apply this idea to the employment contract and explore some of the empirical implications.

In the context of employment, a "normal" good or service is one for which there are well defined expectations for performance. In this case default might occur, but it is not the norm. Williamson calls this a contingent claims contract. This is because terms are clear, and depending upon the realized state, there are well defined services and payments expected by both parties. In contrast, a "complex" good or service is one for which performance cannot be clearly specified in advance. An example of this would be research and development activities where the job entails innovation that the employer cannot specify in advance.

This leads us to characterize jobs differently from Brown (1992) or Lazear (1986). In our model wage labor is viewed as supplying a "normal" good. The individual 
agrees to supply a certain number of hours of acceptable performance, in exchange for a wage per hour. Thus we place hourly work into what Williamson et al. (1975) call contingent claims contracting. In contrast, while Brown (1992) also includes salary work in this category, we explore the idea that salary jobs often do not have clear performance expectations. In many situations salaried employees may work longer hours than the norm (for which they are not directly compensated) to meet unexpected demand at work. Thus we categorize salary work as part of complex exchange.

Consider now workers who are paid additional compensation above their wage or salary. For example, piece rate and commission contracts link compensation to clear performance measures. Hence we consider these to also be examples of contingent claims contracting. In contrast, merit and bonus pay are determined via subjective supervisor evaluations. We view these as examples of complex exchange where performance is evaluated in the absence of clear performance expectation that are specified ex ante.

This approach provides a resolution to Brown (1992)'s finding because within our framework bonuses and merit pay do not naturally situate themselves between fixed wage contracts and contingent pay systems, such as piece rates and commissions. We explore how the transaction cost view of the employment relationship can explain contract form by following workers over time as they change jobs. We do this using the Panel Study of Income Dynamics - PSID. This data set is merged with data on job characteristics using the Dictionary of Occupational Titles (DOT), data that has become the standard for measuring the skill content of jobs (see Autor et al. (2003)). ${ }^{3}$

Since we can follow workers over time as they change jobs, we can explore the relationship between job characteristics and contract form holding worker characteristics fixed. In the next section we introduce a model that details the predictions of 
transaction cost theory for this data. The theory incorporates the three costs highlighted by Williamson (1981) - asset specificity, frequency of trade and uncertainty. We build upon the relational contracts literature for the employment relationship, as developed by Bull (1987) and MacLeod and Malcomson (1989). In these models contract incompleteness is very stark - it is assumed that there are no contractible states ex ante, nor do the models provide an obvious way to empirically implement a partially incomplete contract. A potential solution to this problem is provided by Abreu et al. (1991) who provide a new way to introduce uncertainty into the repeated prisoner's dilemma problem. This is the base model for relational contract theory. The decision to defect in a prisoner's dilemma game can be viewed as a way to capture Williamson's notion of opportunism, while the information structure they introduce provides an elegant way to model both the frequency of trade and uncertainty.

The careful modeling of the frequency of exchange and uncertainty yields results that are not available with the standard repeated game approach to relational contracts. Specifically, the intuition in the standard theory is that frequent trade allows parties to respond more quickly and hence reduces the potential for opportunism. From the transaction cost perspective this intuition suggests that high frequency transactions can be mediated via the market. Abreu et al. (1991) show that this is not necessarily the case when it takes time to learn about performance. This allows one to define the two extreme types discussed above: normal goods or services and innovative goods or services with the feature that much of the time there is no performance, but sometimes the worker may make a useful discovery.

To this base model we also add asset specificity and derive two results. First, for normal services - services for which one can precisely specify expectations in advance - efficient effort can be implemented with contingent claims contract. This can either be a piece-rate/commission contract, or a fixed wage contract, combined with the 
threat of dismissal. We consider this latter case in some detail and show that it results in excessive quits and layoffs as in Hall and Lazear (1984).

When transaction costs correspond to the case of a complex service - a service for which performance cannot be guaranteed - then the employment contract entails subjective evaluation that can be linked to compensation. Given that evaluation is subjective, employers have an incentive not to reward deserving employees. This opportunism is solved by the employee threat of leaving the firm - a necessary condition for this to be an equilibrium is that the employee faces no earnings loss from job changes. It is also the case that matching can be more efficient in this case relative to the case of a normal good because variable pay can be adjusted to reflect market conditions and thus reduce voluntary quits.

After detailing the model and its empirical implications, we explore these empirical implications with the data taken from the Panel Study of Income Dynamics (PSID) and merged with data from the Dictionary of Occupational Titles (DOT). After controlling for worker characteristics, we find that job characteristics are strongly correlated with observed compensation form. These results are consistent with the hypothesis that transaction costs are a significant determinant of the way in which workers are paid.

With respect to rents on the job and selection we have two sets of results. First, we have strong evidence of positive selection into complex jobs as characterized by non-contingent pay. This is consistent with the interpretation of these jobs as being "innovative". We also have evidence that within workers, moving to a complex or non-contingent pay job is associated with higher earnings. However, when we look at turnover at the market level our results are consistent with the hypothesis that wages are set competitively - moving from the market to either type of jobs is not associated with any rents. 
However, we do have some evidence of relation-specific investment. Workers who are laid off face an earnings loss. We also find that workers in complex jobs have a lower rate of turnover. This is consistent with the existence of a relational contract for these workers that allows for more efficient matching (consistent with our earlier findings in Lemieux et al. (2012)).

\section{On the Link Between Transaction Costs and Con- tract Form}

In this section, we introduce a simple model that illustrates the interplay between transaction costs, modes of governance and legal rules. The model distinguishes between different types of labor, and then relates the characteristics of labor to the optimal contract. The next section introduces the basic model. The technical details characterizing the optimal allocation are to be found in the appendix. An innovation of this model is that it endogenizes the match decision and illustrates the role that relation-specific investments play in complex relationships to extend match duration. This is followed by a derivation of the contracting modes for each class of transaction costs.

\subsection{Normal versus Innovative Labor}

The model extends MacLeod (2007) to allow for endogenous turnover and investment, and how they are related to transaction costs. It includes as a special case the well known efficiency wage model of Shapiro and Stiglitz (1984). The transaction cost perspective is built upon three attributes: asset specificity, frequency, and uncertainty. ${ }^{5}$ We begin with asset specificity and suppose that the firm and worker make specific 
investments, $I$ and $i$ respectively, and then trade repeatedly until they decide to separate. The investment $I$ is interpreted as worker training that is a prerequisite to have a productive worker. The investment $i$ generates a flow utility to the worker of $u^{s}(i)>0$ that is strictly concave in investment. This corresponds to moving closer to one's place of work, making friends at work, and any other investment activity that makes employment with this firm more valuable. In addition to these investments, we consider a number of transaction costs.

Next, frequency is measured by the number of times trade/contracting can occur in a period. The frequency of trade affects two countervailing forces. The first is the less frequent is trade, then the larger the potential costs from breach by one party, and the longer before damages can be assessed. The second is in terms of information. The longer the period, the more accurate is the information regarding performance.

Let $\Delta>0$ denote the length of time for a single transaction, then the frequency of trade is given by $f=\frac{1}{\Delta}$. We follow Abreu et al. (1991), and suppose that the flow of benefits and costs, as well as the flow of information, remains fixed, thus increasing $f$ decreases the value of a single transaction as well as the amount of information regarding the quality of the good. This allows one to explore the effect of changing the arrival time of information while holding the value of trade per period fixed.

Finally, we introduce uncertainty via employee effort. During the period of length $\Delta$ the employee selects effort $q \in[0,1]$. Effort is normalized to be between zero and one so we can interpret effort as a probability whenever convenient. As a matter of convention, $q=0$ denotes low effort, while $q=1$ denotes high effort. The flow cost of effort to the worker is $c(q)$, where $c, c^{\prime}, c^{\prime \prime}>0$ and $c(0)=0$. We show that transaction costs due to uncertainty can be further refined as a function of two potential outcomes.

The first outcome is a bad outcome resulting in a harm of $L \geq 0$. This would correspond to jobs where the worker is supposed to be attentive - say driving a bus or 
aircraft, or monitoring a generating facility. In these cases good performance means avoiding an accident. The probability of an accident is given by $\lambda_{b}(q, \Delta)$, with the property that $\partial \lambda_{b} / \partial q<0$. Our assumption that the quality of information does not change with the frequency of exchange implies that the likelihood of an accident should decrease with the length of the period. We suppose that this probability can be approximated by a Poisson process and let:

$$
\lambda_{b}(q, \Delta)=\gamma_{b}(q) \Delta
$$

where $\gamma_{b}(q)>0$ is a Poisson parameter satisfying $\gamma_{b}^{\prime}<0, \gamma_{b}^{\prime \prime}>0$.

If one sets $\gamma_{b}(1)=0$, and $\gamma_{b}(0)>0$, then this corresponds exactly to the efficiency wage model of Shapiro and Stiglitz (1984). In that case, if the worker chooses high effort $(q=1)$ then the bad event never occurs. When the worker shirks, $(q=0)$ then the bad event follows a Poisson process. This model is rather restrictive for two reasons. First, even when a worker does not shirk, in practice adverse events may occur. Second, the model is most appropriate for what MacLeod (2007) calls a normal good. These are goods for which spot market transactions are appropriate-most of the time the good supplied has the proper quality, but sometimes there is a failure.

In this setup, it is assumed that the firm can verify the worker's presence on the job. Hence compensation is for a well defined service. We could allow the job to have a formal performance measure, as with piece-rate jobs or sales jobs where the individual is paid a commission. Both cases are examples of normal goods because performance expectations (production of a unit or sales) are discrete, well defined outcomes for which there is an agreed upon price. Sometimes things may go wrong. A piece may have a defect, or a sale may face a legal hurdle. In either case, we view these as infrequent events for which there would be some explicit settling up. 
Individuals may also be employed in jobs where the service produced is an innovative good. By this one means that there is no chance of a bad outcome, but good outcomes may be infrequent. This might be the invention of a new idea or software development. It is the opposite of a bad outcome. Over short periods of time good outcomes are very unlikely, while they become more likely over longer periods. In this case we suppose that the value of the good outcome is $G>0$, and occurs with probability:

$$
\lambda_{g}(q, \Delta)=\gamma_{g}(q) \Delta
$$

where $\gamma_{g}$ is a Poisson parameter that satisfies $\gamma_{g}(0)=0, \gamma_{g}^{\prime}(q)>0, \gamma_{g}^{\prime \prime}(q)<0$ for all $q \in[0,1]$. More generally, we will identify innovative goods with complex services that characterize a wide variety of employment relationships in the US, including software production, consulting services, litigation, and so on.

Payoffs can be expressed in either flow or stock terms, depending on which provides the most convenient expression. Flow terms are in lowercase, while stock terms are in upper case. We can summarize the discounted payoff from trade in period $t$ for the firm and worker for a normal good as follows:

$$
\begin{array}{cl}
\text { Firm: } & \Pi_{t}=\Delta\left(v_{t}-w_{t}-\gamma_{b}\left(q_{t}\right) L\right)-B_{t}+\delta \Pi_{t+1} \\
\text { Worker: } & U_{t}=\Delta\left(w_{t}-c\left(q_{t}\right)+u^{s}(i)\right)+B_{t}+\delta U_{t+1}
\end{array}
$$

where $\delta=e^{-r \Delta}$ is the one period discount factor. For high frequency trade we use the approximation $\Delta \cong \frac{(1-\delta)}{r}$ and so the flow terms are simply multiplied by $\Delta$. The term $v_{t}$ is the flow return from the services provided by the worker-in general these may vary due to business cycle fluctuations. To simplify matters we suppose that the flow payoffs are i.i.d. log normal distributions, where $v_{t}$ has a mean of $\bar{v}$ and variance 
$\sigma_{v}^{2}$. The flow wage is given by $w_{t}$ which is agreed upon at the beginning of period $\mathrm{t}$ (and might be part of a long term agreement). We suppose that the firm may choose a stock transfer $B_{t}$ in any period.

In principle the transfer $B_{t}$ could have any sign, but in practice we are thinking of employment situations where the worker cannot fully indemnify the firm for losses. If she could, then we would conceptually be in a situation where the employee could be sub-contractor. Our elemental model of the employment relationship is that the employee cannot fully indemnify the firm, and for simplicity we suppose that $B_{t} \geq 0$. In the model $B_{t}$ is an explicit bonus payment. However, it can also be viewed as promotion within a firm - in salary jobs workers can be rewarded by subjectively determined promotions. Similarly, should the firm dismiss the worker to hire a replacement it is assumed that the firm must bear a training cost $I$.

It is further assumed that the market is perfectly competitive, with the firm's outside option if no worker is hired set to $\Pi^{0}=0$. The flow utility from leaving a job in period $t$ is denoted by $u_{t}$ with mean $\bar{u}$ and variance $\sigma_{u}^{2}$. Hence we have the worker's outside option:

$$
U_{t}^{0}=u_{t} \Delta+\delta \bar{u} / r
$$

Under these assumptions, there will always be a positive probability that there should be separation and employment each period.

The case of innovative goods is exactly the same - we simply replace $-\gamma_{b}\left(q_{t}\right) L$ by $\gamma_{g}\left(q_{t}\right) G$ in the expressions above. In summary, all the functions are taken as given. The vector of parameters that describes the physical characteristics of the relationship is given by:

$$
x^{b}=\{\Delta, L, I\}, x^{g}=\{\Delta, G, I\}
$$

A paradigm normal service is given by $x^{b}$, while a complex service is given by $x^{g}$. 
When appropriate we let $x$ denote either type of service. In addition, there are the time varying parameters:

$$
z_{t}=\left\{v_{t}, u_{t}\right\}
$$

The timing of the model is as follows. In period zero, the firm and worker decide whether there is a match or not, and then make their investments $I$ and $i$. This decision is given by the firm's investment decision $I_{0} \in\{0, I\}$, where $I_{0}=I$ indicates employment. After that we have the following sequence of decisions in periods $\mathrm{t}=1,2, \ldots$ :

- Period t.1: The firm privately observes $v_{t}$ and the worker privately observes $u_{t}$.

- Period t.2: Parties decide to continue or terminate their relationship based upon the new information and the history of the relationship. This results in $e_{t} \in\{0,1\}$

- Period t.3: The worker privately chooses effort $q_{t} \geq 0$.

- Period t.4: The good and bad outcomes are observed by both parties.

- Period t.5: The firm pays a wage, $\Delta \times w_{t}$ and a bonus $B_{t} \geq 0$.

The endogenous real variables are whether or not there is employment, indicated by $I_{0} \in\{0, I\}$, the worker's investment $i$, the employment continuation outcome, $e_{t} \in\{0,1\}$ and effort by the worker, $q_{t} \in[0,1]$. Let $y_{0}=\left\{I_{0}, i\right\}$, and $y_{t}=\left\{e_{t}, q_{t}\right\}$ denote the endogenous outcome of the model for $t=0,1,2 \ldots$ The price terms, $c_{t}=\left\{w_{t}, B_{t}\right\}$, are determined by the contract in place that we denote by $C$.

The level of effort is independent of time, hence when the efficient levels are 
between 0 and 1 , they are uniquely defined by:

$$
\begin{gathered}
\gamma_{b}^{\prime}\left(q_{b}^{*}\right) L=c^{\prime}\left(q_{b}\right) \\
\gamma_{g}^{\prime}\left(q_{g}^{*}\right) G=c^{\prime}\left(q_{g}\right)
\end{gathered}
$$

This implies that optimal effort increases with L and G. If $\gamma^{\prime}(1) L>c^{\prime}(1)$ then $q_{b}^{*}=1$ and similarly for $q_{g}^{*}$. In this model productivity fluctuates and hence depending upon the realizations of $z_{t}$ there may be separation. In the appendix we show that the value function is well defined, and there exists a set of states under which the relationship continues. This also implies a unique level of relation-specific investment by the worker. In the model we allow for idiosyncratic shocks each period. An implication of this is that as the frequency of trade increases the probability of separation at the optimal allocation falls! The reason is that these shocks are short run effects, and the value of the relationship depends upon the long run returns. This result will allow us to illustrate how transaction costs can lead to failure to trade, even when the frequency of transactions is high, a result that is the opposite of the intuition for standard relational contracting models.

\subsection{Contracting Modes}

In this section we explore the implications of transaction costs for observed contracting modes. Holmes (1897) observes that a contract is nothing more than an agreement to supply services, which if breached, implies that damages are due - this corresponds exactly to Williamson (1981)'s notion of black letter law. When contracts are incomplete, then courts may not have the information necessary to impose appropriate damages. In these cases parties rely upon relational contracting. By this we mean in the event of breach, either the employee is dismissed, or she quits to find a better 
employer. Adding uncertainty regarding match quality means that when separation is observed we do not know if it is due to contract breach or due to an adverse productivity shock. In the next two subsections we explore the implications of these for the observed employment contract.

\subsubsection{Normal Labor Services}

Consider a long term contract with normal labor services, in which case $G=0$ and there is a possibility of a loss $L>0$ from accidental non-performance. It is assumed that this loss is sufficiently large that in any period the firm cannot write a binding contract to have the worker pay $L$, and hence $B_{t} \geq 0$. One might use a long term wage cut in the face of a loss, but as a general policy this is not sustainable because multiple losses would result in wages being below her alternative, and hence would not be credible. At some point dismissal would be the final penalty available to the firm.

Under such a scenario the only possibility is employment at will at a fixed wage, combined with dismissal if a loss occurs. In order for there to be a loss associated with firing it must be the case that the wage is set above the market alternative. To characterize the solution we derive the payoffs as a function of the endogenous variables $(i, q, w)$. Firm profits in state $v_{t}$ are given by:

$$
\Pi\left(v_{t}, i, q, w, \Pi^{*}, I\right)=e\left(v_{t}, u_{t}, \Pi^{*}, U^{*}\right)\left(\left(v_{t}-\gamma_{b}(q) L-w\right) \Delta+\delta \Pi^{*}-\delta \gamma_{b}(q) \Delta I\right)
$$

The employment term $e$ is 1 if there is a match and zero otherwise. It depends upon both firm and worker states since either might choose to leave for better alternatives. In addition, if the worker is fired when a bad outcome occurs, then the firm hires a new worker at a cost $I$ in the current period, and gets the same expected return $\Pi^{*}$ in 
the following period. Notice that since the firm faces a loss when firing the worker to be replaced with an identical worker then this is not efficient. In order to sustain this behavior as an equilibrium MacLeod and Malcomson (1989) show that one requires a set of self-enforcing social norms with the feature that the worker shirks if she is not dismissed after an adverse event, reinforced by the firm's promise to dismiss if there is an accident.

Similarly, the worker's utility is given by:

$$
\begin{gathered}
U\left(u_{t}, i, q, w, U^{*}\right)=e\left(v_{t}, u_{t}, \Pi^{*}, U^{*}\right)\left(\left(w-c(q)+u^{s}(i)\right) \Delta\right. \\
\left.+\delta\left(\left(1-\gamma_{b}(q) \Delta\right) U^{*}+\gamma_{b}(q) \Delta \bar{U}\right)\right)+\left(1-e\left(v_{t}, u_{t}, \Pi^{*}, U^{*}\right)\right)\left(u_{t} \Delta+\delta \bar{U}\right)
\end{gathered}
$$

The first term is the payoff if there is employment. If the bad outcome occurs, then the worker is fired. Solving for the equilibrium requires a number of steps. As in the case of the efficient matching problem, we solve for worker effort first:

$$
c^{\prime}(q)=-\gamma_{b}^{\prime}(q)\left(U^{*}-\bar{U}\right)
$$

This is a standard expression from the efficiency wage literature-the incentive to the worker depends upon the effect of effort upon the probability of an accident $\left(\gamma_{b}^{\prime}<0\right)$ and the difference from continuing employment and leaving $\left(U^{*}-\bar{U}\right)$. By increasing the wage the firm increases this incentive, but the wage also increases the turnover rate from dismissals. In the original efficiency wage model of Shapiro and Stiglitz (1984) this turnover is exogenous. Here we extend this result to the case with endogenous matching in the presence of asset specificity and uncertainty.

It is also worth highlighting the assumption that uncertainty regarding the inside and outside options are non-contractible is key to ensuring that the fixed wage is the 
only incentive compatible contract, as shown in Grossman and Hart (1981). This expression shows that we can write quality as an increasing function of $U^{*}: q^{*}\left(U^{*}\right)$. Observe that the current wage has no effect on incentives. Rather, wages affect incentives because they are assumed to be constant over time. This implies that a rise in the wage raises future returns from employment, increasing the incentive to work hard in order to reduce the likelihood of dismissal. This efficiency wage effect would not be present if wages were set each period equal to the market rate.

The incentive for the worker to make specific investments is given by (17) in the appendix, where $\rho$ is the probability that the worker keeps her job in equilibrium. To compute the probability in this case we solve for the employment conditions in period $t$ : Let $e\left(v_{t}, u_{t}, \Pi^{*}, U^{*}\right)=1$ if and only if these conditions hold: ${ }^{6}$

$$
\begin{aligned}
& u_{t} \leq w+u^{s}(i)-c\left(q^{*}\left(U^{*}\right)\right)-\delta \gamma_{b}\left(q^{*}\left(U^{*}\right)\right)\left(U^{*}-\bar{U}\right)+\delta\left(U^{*}-\bar{U}\right) / \Delta \\
& v_{t} \geq w+\gamma_{b}\left(q^{*}\left(U^{*}\right)\right)(L+\delta I)-\delta \Pi^{*} / \Delta
\end{aligned}
$$

In the appendix we show that the efficient matching conditions depends only upon $v_{t}-u_{t}$ (see (17)) and hence (5) and (6) imply excessive quits and layoffs, as in Hall and Lazear (1984). When we come to innovative goods in the next subsection, we shall see that bonus pay may improve both performance and matching relative to an efficiency wage contract. Also notice that as the time period gets shorter $(\Delta \rightarrow 0)$, then the probability of separation falls, all else held fixed. This is quite nice, and shows that increasing the frequency of trading does not necessarily imply a shorter relationship. This is increasing in $\Pi^{*}$ and $U^{*}$ and $i$. Using the techniques outlined in the appendix we can show the existence of equilibrium profits and utility given wage and investments that are consistent with this matching rule. Let the solutions be denoted by $\Pi^{*}(w, i, I)$ and $U^{*}(w, i, I)$. Given these payoffs, the worker next chooses 
her investment:

$$
i^{*}(w, I)=\operatorname{argmax}_{i \geq 0} U^{*}(w, i, I)-i
$$

The effect of wages upon investment cannot in general be signed because it depends upon two countervailing effects. When $w$ is larger, the probability of dismissal is larger due to the inside option $v_{t}$. This is determined by (6), and is independent of the positive effect of $i$ upon employment via (5), which is determined by the worker's outside offer. All we can say is that it is continuous. We complete the solution by solving the firm's problem:

$$
\begin{aligned}
& w^{*}(I)=\operatorname{argmax}_{w \geq 0} \Pi^{*}\left(w, i^{*}(w, I), I\right) \\
& \text { subject to }: \\
& U^{*}\left(w, i^{*}(w, I), I\right)-i^{*}(w, I) \geq \bar{U}
\end{aligned}
$$

Thus we have:

Proposition 1. The relational contract for a normal service consists of a fixed wage $w^{*}$. Employment occurs if $\Pi^{*}\left(w^{*}, i\left(w^{*}, I\right), I\right) \geq I$. Under such a contract we have:

- Employment is at will.

- Quits and separations are higher than at the first best.

The result regarding employment at will follows from assuming $L$ is not contractible, but observable by the worker and firm. If $L$ were contractible, and one could use it as the basis for a dismissal, then the firm would simply add a severance payment $S$ if the worker is dismissed without cause. This payment would be set to optimize the turnover rate separately from the incentive effect of the higher wage. Since employment is at will, this implies that voluntary quits lead to future wages being greater 
than or equal to current wages. Similarly, involuntary separations lead to a loss of utility for the worker.

\subsubsection{Innovative/Complex Labor Services}

Consider now innovative services for which $L=0$ and $G>0$. If the bonus is contractible, then the employment contract can specify a reward when $G$ is realized. In contrast to the normal service case above, this can ensure efficient production when the firm is assumed to always be solvent. Suppose that $G$ is observable by the worker and firm, but not contractible, as in MacLeod and Malcomson (1989).

The solution procedure will be similar to the case of a normal service, but the difference now is that the rare event is good news, and hence the firm pays a bonus $B$ whenever the good outcome $G$ is realized. This implies that the worker has a simple static optimization exercise. To ensure that the bonus is paid the worker can use the threat of a quit as an enforcement mechanism when the firm does not pay a promised bonus. The employment decision $e\left(v_{t}, u_{t}, \Pi^{*}, U^{*}, i\right)$ is the solution to (5) and (6) with the addition of a bonus term, $\gamma_{g}(q) B$ for the worker, and the replacement of $-\gamma_{b}(q) L$ with $\gamma_{g}(q) G$ for the firm. The payoff functions for the firm and worker are now:

$$
\begin{gathered}
\Pi\left(v_{t}, i, q, w, B, \Pi^{*}\right)=e\left(v_{t}, u_{t}, \Pi^{*}, U^{*}, i\right) \times \\
\left(\left(v_{t}+\gamma_{g}(q)(G-B)-w\right) \Delta+\delta \Pi^{*}-\delta \gamma_{b}(q) \Delta I\right)
\end{gathered}
$$




$$
\begin{aligned}
& U\left(u_{t}, i, q, w, B, U^{*}\right)=e\left(v_{t}, u_{t}, \Pi^{*}, U^{*}, i\right)\left(\left(w-c(q)+\gamma_{g}(q) B+u^{s}(i)\right) \Delta\right. \\
+ & \left.\delta\left(\left(1-\gamma_{b}(q) \Delta\right) U^{*}+\gamma_{b}(q) \Delta \bar{U}\right)+\left(1-e\left(v_{t}, u_{t}, \Pi^{*}, U^{*}, i\right)\right)\left(u_{t} \Delta+\delta \bar{U}\right)\right)
\end{aligned}
$$

With bonus pay the worker solves a static, rather than a dynamic problem:

$$
c^{\prime}(q *(B))=\gamma_{b}^{\prime}\left(q^{*}(B)\right) B
$$

Next, one has an incentive constraint for the firm for the bonus payment. In order to enforce the bonus payment the worker has to threaten to quit should a bonus not be paid in the event of a success. Under the assumption that there are no reputation effects, then the firm will hire a new worker, and hence the cost is given by the investment in worker training. Thus we have:

$$
B \leq \delta I
$$

This illustrates that a necessary condition for the use of bonus pay is the existence of a relation-specific investment by the firm.

We begin with the case in which the firm promises the same bonus $B$ each period. Then from an analysis similar to the one in the previous section, there exists payoffs 
of the form $\left(\Pi^{*}(w, B, I), U^{*}(w, B, I)\right)$, and the optimal contract solves:

$$
\begin{aligned}
\max _{w, B \in \Re_{+}^{2}} \Pi^{*}(w, B, I) & \\
\text { subject to }: & \\
U^{*}(w, B, I)-i^{*}(w, B, I) & \geq \bar{U} \\
B & \leq \delta I
\end{aligned}
$$

An interesting feature of this optimization problem is that the individual rationality constraint for the worker might not be binding. The reason for this is that worker turnover may be costly for the firm, and hence it may offer a utility above the market. This is a point first made by Hashimoto (1981). This effect is quite different from the case of a normal service. There employee utility was necessarily above the outside option in order to provide incentives for performance. In this case, the rent may exist to ensure better matching. Both cases illustrate how transaction costs and incomplete contracts may lead to rents for a variety of reasons.

The continuity of payoffs in (9) ensures that a solution exists, though whether or not the worker is paid above her outside alternative depends upon the parameters of the model. We will empirically look for evidence of rents in the next section. The results for this case are summarized as follows:

Proposition 2. The relational contract for a complex service consists of a fixed wage $w^{*}$ and a bonus $B^{*}$ that is paid whenever there is a good outcome. Employment occurs if $\Pi^{*}\left(w^{*}, i\left(w^{*}, I\right), I\right) \geq I$. Under such a contract we have:

- Employment is at will.

- Quits and separations are higher than at the first best. 
- Off equilibrium, quits due to non-payment of a bonus might lead to a higher income at the new firm.

As before, with at will employment voluntary quits result in higher future wages. However, since involuntary separations can occur due to an exogenous drop in firm productivity, then in a competitive market workers may not face a wage loss when changing jobs.

\subsection{Summary}

These results illustrate how job characteristics, as defined by whether the labor service is normal or innovative/complex affects optimal contracting. The former are characterized by an explicit wage for a unit of output. Moreover, termination can occur either because of an adverse productivity shock, or because performance was poor. The analysis for piece-rate or commission contracts would be similar. In that case, parties agree on a price for each unit of output. However, should the service delivered be unsatisfactory, then the firm would have to dismiss the employee.

In contrast, a complex service entails bonus pay. In addition to being observationally different due to the existence of bonus pay, it also has the feature that layoffs occur only due to a productivity shock. This has the implication that if all parameters are the same and $G=L$, then we would expect both the layoff rate and the associate wage loss to be lower in complex jobs.

There is an additional difference. Suppose the worker and the firm can observe the state of the economy, say $s \in\{L, H\}$. In the $L$ state, the outside option for the worker is lower. In that case, since bonus pay is non-contractible (in contrast to the contractible wage in the normal good case), then parties could agree to lower bonuses in the $L$ state. This would entail lower effort by the worker (since the lower 
bonus would be agreed upon before the worker chooses effort). This would relax the individual rationality constraints and allow parties to get closer to efficient matching (full contractibility upon $\left(v_{t}, u_{t}\right)$ would allow for first best matching).

In summary, the introduction of transaction costs based solely upon the characteristics of the job, as opposed to the worker, leads to a rich set of empirically testable implications. Jobs where we observe bonus pay are likely to be more complex, as well as more durable. In normal jobs turnover can lead to a utility loss to the worker. In contrast, for bonus pay jobs turnover is always voluntary and hence there should not be any wage loss. We will explore these implications using a panel of US workers. The panel aspect allows us to control for worker characteristics. Hence, any variation in observed contract form arises from variation in job characteristics rather than worker characteristics.

\section{The Data}

In this paper we combine two data sets, one containing information about the task content of occupations, and the other containing the usual survey questions about labor market outcomes and socioeconomic characteristics such as hourly earnings, education, race, marital status, etc. The fact that those two data sets both include the Census 1970 occupation codes allows us to merge the two and assign to each individual worker the task content measures associated with his occupation.

The goal of the empirical analysis is to explore the idea that employment can be viewed through the lens of transaction cost economics that divides jobs into normal and complex jobs. Normal jobs corresponds to occupations for which there is a clear performance obligation. In that case, performance expectations can be set in advance in exchange for a fixed wage. Separation occurs if there is non-performance or it is no 
longer in the interests of either party to continue with the relationship. We use the Dictionary of Occupational Titles (DOT) to provide some exogenous measure of job characteristics that can be viewed as characterizing normal exchange. We can then ask if firms in which workers are in such occupations are more likely to use fixed wage contracts.

Similarly, some jobs require workers to use judgment and hence performance cannot be easily defined in advance. For those we ask if they are associated with more use of salaried compensation and bonus pay. The theory suggests that these jobs would rely more upon relation-specific investment into worker skill, and hence there should be rents upon dismissal, and a lower likelihood of a layoff during a downturn compared to other jobs. The rest of this section describes the data we use in more detail. The following section discusses the empirical evidence.

\subsection{The 1977 Dictionary of Occupational Titles (DOT) and its 1991 Revision}

We use the DOT to measure the characteristics of a job that, according to transaction cost theory, should affect the form of compensation used by the firm. In their paper on the link between worker skills and the task content of occupations, Autor et al. (2003) (ALM) exploit the information contained in the DOT on a wide variety of occupation characteristics measured at the 4 digit level. Note that ALM use both the 1977 4th Edition version of the DOT as well as the 1991 revised 4th edition. ${ }^{7}$ Therefore it is possible to exploit variations in task content both across occupations as well as across time within occupations.

We focus on the same five measures of task content used by ALM namely nonroutine manual, routine manual, non-routine cognitive-interactive, routine cognitive, 
and non-routine cognitive-analytical. The following table describes the task content that those five DOT variables are meant to measure (a somewhat different and more detailed description can be found in Appendix 1 of Autor et al. (2003)).

*********************** Table 1 Here $* * * * * * * * * * * * * * * * * * * * *$

Whereas the focus in ALM is on the degree to which computers can be seen as substitutes or complements in performing those tasks, our goal here is to use the task content of jobs as a measure of transaction costs affecting the way employees are paid. More complex employment relationships involving non-routine cognitive tasks should be associated with different contractual arrangements compared to jobs involving simple repetitive tasks.

Each task measure is originally coded on a continuous scale between 0 and 10 , with 10 representing a more intensive use of the task. We standardize each to have a mean of zero and a standard deviation of one so that the coefficients associated with them can be seen as representing the "impact" of a one standard deviation increase in for example the importance of non-routine cognitive tasks on the probability that the worker is in a contractual arrangement which entails either a salary or a bonus, or both.

\subsection{The Panel Study of Income Dynamics (1976-2004)}

The PSID sample we use consists of male heads of households aged 18 to 64 with average hourly earnings between $\$ 4.00$ and $\$ 300.00$ (in 2008 dollars) for the years 1976-2004, where we obtain the hourly wage rate by dividing total labor earnings by total hours of work, both for the previous calendar year. ${ }^{8}$ This wage measure based on total yearly earnings is preferable to "point-in-time" wage measures that would likely miss infrequent payments (specifically bonuses) of performance pay. The self- 
employed are excluded from the analysis since our measure of performance pay, based on receiving bonuses, commissions, or piece-rates, is defined for employed workers only. We also exclude workers from the public sector.

This leaves us with an initial sample of 31, 276 observations for 3,283 workers. We then merge all those observations by 3-digit Census 1970 occupations to the corresponding 3-digit averages of the DOT task content variables. Since not all observations in the PSID can be matched to the corresponding DOT averages we lose 2,861 observations, resulting in a sample size of 28,415 for 3,090 workers. Note that we match the 1977 DOT averages to the observations in the PSID for the years between 1976 and 1984 while we use the 1991 DOT averages for the years 1985-2004. ${ }^{9}$ All estimates reported in the paper use the PSID sample weights.

\subsubsection{Identifying Performance Pay in the PSID}

For all interview years we are able to determine whether a worker received a bonus or a commission over the previous calendar year through the use of multiple questions. First, workers are asked the amount of money they received from working overtime, from commissions, or from bonuses paid by the firm. ${ }^{10}$ Second, we sometimes know only whether or not workers worked overtime, but not the amount of overtime pay they received. Thus, we classify workers as not having had a variable pay component if they worked overtime. Third, workers who are not paid exclusively by the hour, nor exclusively by salary, are asked how they are paid: they can report being paid commissions, piece-rates, etc., as well as a combination of salaried/hourly pay along with piece-rates, bonuses or commissions. Through this combination of questions, we can identify all non-overtime workers who received performance pay in bonus, commission, or piece-rate form. 


\subsubsection{Defining Non-Contingent Pay Jobs}

Using the information on whether workers are on commissions or not, we can identify those earning a bonus. We define non-contingent pay jobs as employment relationships in which the modal form of pay is one where the worker is paid either just a salary or a combination of being paid a salary and having received a bonus. Employment relationships in which the modal form of pay is one where workers are paid exclusively by the hour or through a combination of hourly pay along with commissions or piece rates are classified as contingent pay jobs. Commissions and piece rate contracts, like bonuses, are a form of variable pay. However, they are contractually agreed upon ex ante to be a function of some well defined performance measures. Hence, they are a form of contingent pay in the sense of Williamson et al. (1975) and, as discussed in the theory section, contingent pay is not expected to be associated with employment relationships involving complex tasks.

Since we use actual payments of bonuses to identify bonus pay jobs, we are likely to misclassify non-contingent pay jobs as contingent pay jobs if some employment relationships are either terminated before bonus pay is received, or partly unobserved for being out of our sample range. This source of measurement error is problematic because of an "end-point" problem in the PSID data. Given our definition of noncontingent pay jobs, we may mechanically understate the fraction of workers in such jobs at the beginning of our sample period because most employment relationships observed in 1976 started before 1976, and we do not observe whether or not bonus pay was received prior to 1976. Similarly, jobs that started toward the end of the sample period may be non-contingent pay jobs but are classified otherwise because they have not lasted long enough for a bonus to be observed. We deal with that problem using a re-weighting scheme that adjusts the distribution of the number of 
times employment relationships are observed at either end of the sample period such that it mimics the distribution over the 1982-1990 period, when there should not be an end-point problem. More details on this re-weighting adjustment are provided in Lemieux, MacLeod, and Parent (2009).

\subsection{Summary Statistics}

In Table 2 we report sample means by type of job. Focusing first on the job characteristics, we can see that there are large differences in the task content across both types of jobs. Non-contingent pay jobs involve more direction, control, and planning of activities ("non-routine cognitive-interactive") as well as quantitative reasoning ("non-routine cognitive-analytical") than is the case in contingent pay jobs, while the opposite is true for jobs that involve either routine tasks or non-routine manual task requirements.

Being in a non-contingent pay job also pays substantially more and workers in them have on average two additional years of education relative to other workers. The two types of jobs are also considerably different along many other dimensions. Individuals in non-contingent pay jobs are much less likely to be unemployed at the time of the interview and are also almost certain not to be covered by a collective bargaining agreement. They also work more hours during the year than their counterparts in contingent pay jobs.

Looking at the differences in task content across job types, there would appear to be a robust relationship between those task content variables and being in a noncontingent pay job. However, it is also quite possible that workers in jobs which involve more non-routine cognitive-interactive tasks are a selected group. In the next

section we address this issue by exploiting the time variation in the DOT variables. ${ }^{11}$ 
******************** table 2 here $* * * * * * * * * * * * * * * * * * * * * *$

\section{Multivariate Analysis}

\subsection{The Effect of Job Characteristics}

In Tables 3 and 4 we estimate the relationship between the DOT characteristics and the incidence of non-contingent pay jobs, controlling for observed heterogeneity. We also control for unobserved worker heterogeneity by using fixed-effect regressions, exploiting the fact that the DOT variables changed following the 1991 revision.

As mentioned above we use the values in the 1977 version for the years between 1976 and 1984, and the 1991 values for all years thereafter. Another source of variation that can be exploited is the fact that workers may change 3-digit occupations, which would imply that the DOT variables would change as well. However, it is likely that

many of those occupational switches represent noise. ${ }^{12}$ To limit the extent of such false transitions, we force the occupation in an employment relationship to be the modal occupation, while not imposing any restrictions on occupational switches that happen at the same time as employer changes.

If we first look at Table 3 we can see that we easily reject the hypothesis that the DOT job characteristics are not related to the incidence of non-contingent pay jobs. In columns [1] to [4] we simply estimate the cross-sectional relationship using either a linear probability model or a probit. As it turns out it does not make much difference whether we use one or the other. The estimates show a consistent pattern of a negative relationship between manual tasks-routine or not-and the non-contingent pay job dummy while there is a strong positive association between the non-routine cognitive-interactive variable and being in a non-contingent pay job (less so for the 
cognitive analytical component). A one-standard deviation increase in the degree to which a job requires direction, control, and planning (the non-routine cognitiveinteractive variable) is associated with an increase in the probability of being in a non-contingent pay job of between 7.5 to $11 \%$, depending on the specification. Note that while adding occupational controls in columns [3] and [4] reduces the estimates somewhat, it does not reduce them to zero. ${ }^{13}$

$* * * * * * * * * * * * * * * * *$ table 3 here $* * * * * * * * * * * * * * * * * * * * *$

As mentioned above, it is possible that selectivity is partly responsible for the estimates reported in columns [1] to [4]. To see whether this is the case, we estimate fixed-effect linear probability models whose results are reported in columns [5] and [6]. In this case the effect of job characteristics is identified by how compensation form changes when a worker moves between jobs with different DOT characteristics. Hence, we are controlling for variations in worker skill. Two main results stand out. First, there is strong evidence of selectivity: the association between the non-routine manual task content variable and being in a non-contingent pay job is basically eliminated once we include worker fixed-effects. Workers performing those tasks are systematically different than those in non-manual tasks and that difference contributed to the estimates reported in columns [1] to [4]. Second, the robust relationship between non-routine cognitive-interactive tasks and being in a non-contingent pay job is still there and is not much different than the one estimated in the cross-section.

In Table 4, we get very similar results if we use a restricted sample made of workers who, in each year of the employment relationship, report being paid a salary and/or receiving a bonus every year (or neither of those in the case of contingent pay jobs) instead of using the modal form of pay.

$* * * * * * * * * * * * * * * * *$ table 4 here $* * * * * * * * * * * * * * * * * * * * *$

To summarize the results shown in Tables 3 and 4, it would appear that conditional 
on observed and time-invariant workers characteristics, a change in the task content across employment relationships leads to a change in the nature of one's job and the associated compensation form. In particular, non-contingent pay appears to be used to compensate workers that are supplying a complex service, as measured by the DOT task content measures.

Our definition of what constitutes non-contingent pay, while reasonable, is nevertheless arbitrary and it would be reassuring if it could be at least partly validated through some form of falsification exercise. In Table 5 we define it differently to see how the results change and in what way. The definition we use is the same as the performance pay job definition used in Lemieux, MacLeod, and Parent (2009). In that paper we defined performance pay jobs as employment relationships in which workers report receiving either a bonus and/or being on commissions or piece rates at least once over the course of that employment relationship. On one dimension-the bonus pay-that definition is similar to the one we chose initially. However, we would expect that the presence of commissions and/or piece rates would make a difference in the estimated relationships between DOT characteristics and the probability of being in a non-contingent pay job. We view jobs in which commissions or piece rates are paid as not being complex in the sense of being associated with non-routine cognitiveinteractive tasks-essentially direction, control, and planning of the firm's activities, and in those jobs worker's pay should be contingent on the observed outcome.

As we can see, while it is still true that job characteristics are related to whether a worker is in a performance pay job, the types of DOT characteristics that are associated with such jobs are not the same as in our base case. In fact, there is little evidence that non-routine cognitive-interactive are related to being in a performance pay job while we find a robust relationship between the measure of routine cognitive tasks and performance pay jobs. Recall that the DOT definition of such tasks is 
"adaptability to situations requiring the precise attainment of set limits, tolerances, or standards". It is interesting to note that this relationship is entirely dependent on performance pay jobs including commissions and piece rates, forms of pay which one would expect to be associated with the DOT definition of what constitutes routine cognitive tasks. If we keep only bonuses, the relationships reverts largely to what we show in Tables 3 and 4.

In summary, these results provide evidence that the lens of transaction cost economics can provide insight into the form of compensation. Firms vary the way they compensate individuals as a function of the characteristics of the service provided by workers.

\subsection{Hourly Earnings and Complex Exchange}

In this section we look at two related questions. We first examine whether workers in non-contingent pay jobs are paid more than in other jobs. We then investigate the question of how much do hourly earnings change when workers transit from job to job. More specifically we look at the following types of transitions: 1) from noncontingent pay jobs to the market, 2) transiting from contingent pay jobs to the market; 3) from the market to non-contingent pay jobs; and 4) transiting from the market to contingent pay jobs. The evidence presented above suggests that complex exchange jobs are associated with non-contingent pay and thus we will operationalize the concept of moving between complex exchange and normal jobs as moving between jobs with different compensation forms.

This way of thinking about moving from job to job is consistent with the way we think about labor market transitions going back to the work of Jovanovic (1979). The alternative for a worker in a relationship is any alternative job. Thus, we do not 
constrain the data to require jobs transitions to a particular type. Rather, consistent with the assumption in transaction cost economics that parties "economize", we suppose that when separation occurs workers find the best alternative match-hence the label "the market", with the form of compensation depending upon the characteristics of the service supplied and not the identity of the worker per se.

In Table 6, we report the estimates from a simple regression of wages on a dummy for being in a non-contingent pay job, including controls for the job characteristics in addition to the usual socio-demographic controls. We can see that there is strong evidence of positive selection into non-contingent pay jobs as the coefficients estimated with fixed-effects are considerably smaller than those estimated by OLS. Still, even after controlling for unmeasured worker characteristics there is a statistically significant difference in hourly earnings of about 3.5\%. Interestingly, whether we control for the task content DOT variables or not does not affect the wage gap even though those variables are statistically associated with wage variations. Thus, our results are consistent with the predictions of Brown (1992)'s model. Since we have a panel, we can more carefully control for worker heterogeneity, thus explaining the differences in our results.

$* * * * * * * * * * * * * * * * *$ table 6 here $* * * * * * * * * * * * * * * * * * * * *$

It is worth recalling that contingent pay jobs are typically wage labor for which workers are carefully metered. In the case of complex exchange the wage is computed using a worker's self-reported hours of work. Given that it is performance, and not hours of work, that is being rewarded these significant effects can easily be due to an under reporting of hours worked in non-contingent pay jobs. The alternative explanation is that there is a compensating differential for these jobs. In either case, the evidence is not supportive of an "efficiency wage" effect for normal jobs relative to complex exchange. 
We can obtain some further insight into this issue by trying to identify whether such a wage differential is present at the start of the employment relationship or instead is minimal at the start and then builds up over the course of that employment relationship. To investigate this question we look at how a worker's wage changes following a transition from one firm to another.

The results are reported in Table 7 where we show the results both for all workers irrespective of whether the separation is a quit or a layoff, and separately. Note that the estimates reported in each column of lines 1 and 2 in Table 7 come from one regression while the estimates reported in lines 3 and 4 are produced from another. For example in column [1], where there is no control variable (and no constant since the two dummies in lines 1 and 2 are mutually exclusive), the estimates in lines 1 and 2 simply represent the raw log wage change between the last time a worker is observed in one employment relationship and the first time he is observed in the next one, irrespective of what type the next job is. Focusing first on the estimates without controls, a conservative way to interpret the results is that there is some evidence of a wage loss when one transits out of a non-contingent pay job. However it is not statistically different from the wage change when a worker leaves a contingent pay job. Adding controls for tenure, year effects, and the interaction of tenure makes it harder to interpret the coefficients estimates on their own although adding those controls makes little difference to the conclusion that there is no difference between the two types of transitions.

$* * * * * * * * * * * * * * * * * *$ table 7 here

Turning to lines 3 and 4 in Table 7, we look at the transition from what we call "the market", meaning that we combine all previous jobs irrespective of compensation form, to either non-contingent pay jobs or contingent pay jobs. Although the estimates are again fairly imprecise, we find no evidence that workers in non-contingent pay jobs 
earn more than in other jobs at the start of the employment relationship.

It is important to point out that using wage changes to infer if workers earn rents or not, either at the end of the previous relationship (lines 1 and 2) or at the start (lines 3 and 4) is problematic. The end of an employment relationship is not an exogenous event, nor is the type of jobs workers transit to following displacement in the previous one. The results in Table 6 suggest that there is a wage premium to working in a noncontingent pay job, although here again, even in fixed-effects models the results are identified from the movement across job types within individuals. While conditioning out unmeasured worker characteristics is certainly an improvement over simple OLS regressions, it still leaves out the problem of endogenous job switches.

Overall the results are consistent with the standard hypothesis in labor economics that wages reflect a worker's skill. There is little evidence that wage levels per se are being used to provide incentives. This does not mean that there are no rents. Central to Williamson et al. (1975)'s theory is that there are significant relation-specific rents. If so we would observe their effects in terms of the turnover rates.

\subsection{Job Attachment}

The theory of efficient matching does not rely upon wages. Rather, if a relationship is more valuable, then it should face a lower probability of termination, regardless of compensation form. In Table 2 we saw that average tenure is longer in non-contingent pay jobs than in contingent pay jobs. In this sub-section we investigate in more detail whether the difference in job duration reported in the descriptive statistics holds up once we incorporate observed and unobserved heterogeneity.

To do so we estimate a so-called "grouped-data"-or discrete-hazard model which allows for time-varying covariates. Essentially, such a model accounts for the fact that 
while the underlying process generating employment duration is continuous, the data is not recorded in continuous format. To incorporate time-varying covariates we follow Jenkins (1995) and "split" employment spells into yearly observations. Covariates are thus allowed to vary across those observations but they are considered fixed within them. Finally we allow for a flexible (piece-wise constant) baseline hazard as well as unmeasured worker heterogeneity modeled as a Gamma distribution, following (Meyer (1990)). ${ }^{14}$

The results are reported in Table 8 in hazard ratio format. A ratio of less than one associated with an explanatory variable means that the regressor reduces the hazard rate out of the employment relationship. We can see that whether we control for unobserved heterogeneity or not, the qualitative conclusion is basically left unchanged: workers in non-contingent pay jobs are much less likely to see the employment relationship being terminated (whether by a layoff or a quit) than workers in other jobs. In other words, the results are not supportive of a simple selection story by which more productive workers who are selected into non-contingent pay jobs also happen to be "low-mobility types".

$* * * * * * * * * * * * * * * * *$ table 8 here

In Table 8 we also look at how local labor market conditions may affect the hazard out of employment differently in non-contingent vs. contingent pay jobs. We use the unemployment rate in the county of residence as a measure of local labor market conditions. Note first that as the local unemployment rate increases, the probability that the job ends increases. This is true whether we control for unobserved heterogeneity or not. Of course, at some level this is not very surprising as part of the relationship has to be basically mechanical if workers sampled in a given county are representative of the population. What is more interesting is the fact that workers in non-contingent pay jobs are affected to a lesser degree than workers in contingent pay 
jobs, as represented by the smaller-than-one odds ratio associated to the interaction between the local unemployment rate and the non-contingent pay job indicator. This is quite strong evidence that there is greater relation-specific investment in those jobs.

\section{Conclusion}

In this paper we have integrated the effect of transaction costs into a dynamic contract model of employment. The model highlights the many interlocking components of an effective employment relationship. Specifically, the employment contract affects the level of relation-specific investment by both parties, the quality of the goods produced, and the conditions under which the relationship continues. We show that one element of transaction costs concerns the pattern of cost and rewards from a relationship. Normal goods have a well defined performance standard. In the case of wage labor breach leads to employee dismissal. When performance can be measured then workers can be compensated as a function of their measured performance. In either case the optimal contract entails a fixed wage or enforceable performance pay combined with employment at will. In contrast, complex jobs are characterized by the difficulty of specifying worker performance in advance. In that case, the employment contract is characterized by subjective bonus pay, with the threat to leave providing an incentive to the firm to treat the worker fairly.

This perspective allows us to divide jobs in the US into two groups, roughly corresponding to normal and complex jobs. We find that DOT variables that can be interpreted as measures of job complexity are associated with the use of bonus pay. We also find that there is more job security in bonus pay jobs, consistent with Williamson's prediction that relation-specific investments play a role determining governance. However, we find mixed evidence of rents. This suggests that there 
is little direct evidence of efficiency wage effects - workers receiving rents to ensure performance. The results are consistent with standard labor economics assumption that wages reflect worker ability.

This result is consistent with the transaction cost perspective that views observed institutions as efficient adaptation to economic conditions. In particular, our results are consistent with the hypothesis that observed employment contracts are a response to the problem of effective governance of workers in the presence of relation-specific investments, and uncertainty regarding what constitutes acceptable job performance. This work complements the existing literature that explains how compensation form varies with changes in worker characteristics (Lazear and Oyer (2012)). In this panel, we also find that complex services, and associated performance pay, results in higher compensation. Thus, we find that there is positive selection into complex jobs.

Our results provide a resolution for the puzzling results of Brown (1992). He used the lens of agency theory which places merit pay as an intermediate case between fixed wage contracts and explicit performance contracts. Transaction cost economics build upon an older, legal tradition that suggests an alternative way to model these contracts. From a transaction cost perspective, both fixed wage contracts and explicit performance pay correspond to contingent claims contracting.

In contrast, salary work and merit pay contracts have in common that the performance obligation is ill-defined. In that case, it is optimal to use a ralational contract. Moreover, we find that there is positive selection into these contracts, as well as evidence that they are more durable. This is consistent with a transaction cost perspective which predicts a higher level of relation-specific investment. Thus, we have shown that the introduction of transaction costs into a model of employment can provide a way to organize data on contract form. 


\section{A Appendix: Efficient Allocation}

In this appendix we derive the efficient effort and investment levels. We show that the optimal allocation eventually entails separation with probability 1 . Since the worker and the firm are risk neutral, the efficient allocation is the one that maximizes the net social surplus found by adding profits to utility. Since effort does not affect future returns, it can be determined period by period. Next is the matching rule that has to be determined simultaneously with the level of relation-specific investment by the worker. Finally, wages can be set so that both parties prefer employment whenever it is efficient.

The value of effort in each period is given by:

$$
V(q, \Delta)=\gamma_{g}(q) \Delta G-\gamma_{b}(q) \Delta L-d(\Delta) c(q)
$$

Our assumptions ensure that $V_{q q}<0$, and hence there is a unique solution to:

$$
q^{*}(\Delta)=\max _{q \in[0,1]} V(q, \Delta)
$$

Since the objective function is strictly concave, then we know there is a unique solution. It is completely characterized by the following conditions. If $V_{q}(0, \Delta) \leq 0$, then $q^{*}(\Delta)=0$. If $V_{q}(1, \Delta) \geq 0$ then $q^{*}(\Delta)=1$. If neither case holds, then $q^{*}(\Delta)$ is the unique solution to:

$$
V_{q}\left(q^{*}(\Delta), \Delta\right)=0
$$

Notice that we can do the analysis in terms of flows:

$$
v(q, \Delta)=V(q, \Delta) / \Delta=\gamma_{g}(q) G-\gamma_{b}(q) L-d(\Delta) c(q) / \Delta
$$


Also $\lim _{\Delta \rightarrow 0} v(q, \Delta)=\gamma_{g}(q) B-\gamma_{b}(q) L-c(q)$, and hence for frequent exchange the optimal effort solves:

$$
\lim _{\Delta \rightarrow 0} q^{*}(\Delta)=q^{*}=\operatorname{argmax}_{q \in[0,1]} \gamma_{g}(q) G-\gamma_{b}(q) L-c(q)
$$

We shall suppose that exchange is relatively frequent compared to the discount rate and hence we shall use $q^{*}$ as the optimal level of effort in the subsequent analysis. When we have an interior solution, namely $q^{*} \in(0,1)$ then we have $\partial q^{*} / \partial G, \partial q^{*} / \partial L>0$. If either the benefit $G$ or the loss $L$ is sufficiently large then it is optimal for the worker to set $q^{*}=1$, the maximum effort level possible. This case is important when $c(1) / r<L$ or $G$, because then the cost of obtaining efficient effort may be much less than the loss incurred or the potential benefit. In those cases a firm can earn significant rents by hiring a worker and appropriately incentivizing them.

Next, the optimal matching is determined by maximizing the total surplus found by adding expressions (1) and (2) together. We suppose that $\Delta$ is small enough that we can ignore the effect of the discount rate $r$ in the flow equation. In that case, the dynamic programming equation for the value of the surplus at the beginning of period $t$ is given by:

$$
\begin{aligned}
S_{t} & =S^{*}\left(u_{t}, v_{t}, \alpha\right) \\
& =\max _{e_{t} \in\{0,1\}} e_{t}\left\{\left(v_{t}+\alpha\right) \Delta+\delta E\left\{S\left(u_{t+1}, v_{t+1}, \alpha\right)\right\}\right\} \\
& +\left(1-e_{t}\right)\left\{u_{t} \Delta+\delta \bar{u} / r\right\}
\end{aligned}
$$

where $\alpha=v\left(q^{*}\right)+u^{s}(i)$ is the non-random component flow value of employment and $v(q)=\gamma_{g}(q) G-\gamma_{b}(q) L-c(q)$. This is the value from the relationship that is 
computed after the firm has made its training investment $I$, the worker has invested $i$ into the relationship, and parties have observed the outside $\left(u_{t}\right)$ and inside $\left(v_{t}\right)$ options. The first term is the return from employing the worker one period and then moving to the next period. The second term is the value of the outside option, which has a current realization of $u_{t}$ and then the future expected value is the discounted mean value $\bar{u} / r$. We now have:

Proposition 3. There exists a unique solution to expression 10 such that $S^{*}\left(u_{t}, v_{t}, \alpha\right)$ is continuous and increasing in $u_{t}, v_{t}$ and $\alpha$.

Proof. Let $\alpha=v\left(q^{*}\right)+u^{s}(i)$ be the non-random component of the per period flow returns. We can write the payoff from a match as:

$$
\begin{aligned}
S\left(u_{t}, v_{t}, \alpha\right) & =\max _{e_{t} \in\{0,1\}} e_{t}\left\{\left(v_{t}+\alpha\right) \Delta+\delta E\left\{S\left(u_{t+1}, v_{t+1}, \alpha\right)\right\}\right\} \\
& +\left(1-e_{t}\right)\left\{u_{t} \Delta+\delta \bar{u} / r\right\}
\end{aligned}
$$

At the beginning of period $t$ parties optimally decide whether to continue or not. We have assumed that the payoff in the period and the outside option are i.i.d. random variables. This implies that the expected surplus before the realization of the flows is the same each period. Hence, if the value function exists, then we can define the optimal ex ante surplus as a function of $\alpha$ by:

$$
S^{*}(\alpha)=E\left\{S\left(u_{t}, v_{t}, \alpha\right)\right\}
$$

We will show that this function is the unique solution to a fixed point problem, from which we can derive the function $S\left(u_{t}, v_{t}, \alpha\right)$ using (12).

The expected value of leaving a relationship for a worker is $\bar{u} / r$, where $\bar{u}$ is the 
mean of the distribution of outside options. To solve for the value function, we take $\alpha$ as fixed, and then solve for the value function given $S^{*}$. We then find $S^{*}$ as the solution to a fixed point problem, which will also yield dependence upon $\alpha$.

Given $S^{*}$, the worker and firm stay matched whenever:

$$
\begin{aligned}
\left(v_{t}+\alpha\right) \Delta+\delta S^{*} & \geq u_{t} \Delta+\delta \frac{\bar{u}}{r} \\
v_{t}-u_{t} & \geq \delta\left(\frac{\bar{u}}{r}-S^{*}\right) / \Delta-\alpha
\end{aligned}
$$

Let $\Omega^{E}\left(S^{*}, \alpha\right)$ be the set of $\left(v_{t}, u_{t}\right)$ that satisfy $(14)$, and let the set of states where there is separation be given by:

$$
\Omega^{0}\left(S^{*}, \alpha\right)=\Re_{++}^{2}-\Omega^{E}\left(S^{*}, \alpha\right)
$$

We can now compute the expected value of continuation with optimal matching:

$$
\begin{gathered}
F\left(S^{*}, \alpha\right)=\int_{(u, v) \in \Omega^{E}\left(S^{*}, \alpha\right)}\left(v_{t}+\alpha\right) \Delta+\delta S^{*} f_{u}(u) f_{v}(v) d u d v \\
+\int_{(u, v) \in \Omega)\left(S^{*}, \alpha\right)} u_{t} \Delta+\delta \bar{u} / r f_{u}(u) f_{v}(v) d u d v
\end{gathered}
$$

where $f_{u}$ and $f_{v}$ are the $\log$ normal densities for realizations of $u_{t}$ and $v_{t}$.

This function is clearly an increasing function of $S^{*}$ and $\alpha$ with the properties that $F(0, \alpha)>0$ and $\partial F / \partial S^{*}<1$, hence there exists a unique solution:

$$
S^{*}(\alpha)=F\left(S^{*}(\alpha), \alpha\right)
$$

The final step requires determining the optimal level of relation-specific investment by the worker. The probability that a relationship continues at the end of the period 
is given by:

$$
\rho(\alpha)=\operatorname{Prob}\left\{\Omega^{E}\left(S^{*}(\alpha), \alpha\right)\right\}
$$

which is a continuous and increasing function of $\alpha$.

Thus the present value of the relation-specific investment is given by:

$$
U^{S}(i)=\rho\left(v\left(q^{*}\right)+u^{s}\left(i^{*}\right)\right)\left(u^{s}\left(i^{*}\right)+\delta U^{S}(i)\right)
$$

The result is:

$$
U^{S}(i)=u^{s}(i) \frac{\Delta}{1-\delta \rho\left(v\left(q^{*}\right)+u^{s}\left(i^{*}\right)\right)}
$$

The net benefit from a relation-specific investment is $U^{S}\left(u^{s}, i\right)-i$. Hence this optimal level of investment is the solution to:

$$
d u^{s}(i) / d i=\frac{1-\delta \rho\left(v\left(q^{*}\right)+u^{s}\left(i^{*}\right)\right)}{\Delta}>0
$$

Notice we do not have a term that includes the derivative of $\rho$. The reason for this is that the marginal effect on the payoff is zero via the envelope theorem. The probability of separation is due to the optimal choice between a match and a quit. A small change in the boundary between a match and no match has no effect because the payoff is the same on each side.

The left hand side is monotonically decreasing with $i$, while the right hand side is increasing, hence if a solution exists it is unique. If $d u^{s}(0) / d i<\frac{1-\delta \rho\left(v\left(q^{*}\right)\right)}{\Delta}$, then the only equilibrium is no investment. Notice that a change in parameters resulting in an increase in the probability of a match increases specific investments by the worker.

We can define the expected payoff before the inside and outside options are ob- 
served by:

$$
S^{*}(\alpha)=E\left\{S^{*}\left(u_{t}, v_{t}, \alpha\right)\right\}
$$

This allows us to define the ex ante surplus before the investments are made:

$$
S^{0}(I, i)=-I-i+S^{*}\left(v\left(q^{*}\right)+u^{s}(i)\right)
$$

The next step is to derive the optimal specific investment by the worker. The incentive to invest depends upon how long the worker expects the relationship to last. We can see this by first defining the probability that the relationship continues in any period:

$$
\rho^{*}(\alpha)=\operatorname{prob}\left\{\left(u_{t}, v_{t}\right) \mid v_{t}-u_{t} \geq \delta\left(\bar{u} / r-S^{*}(\alpha)\right) / \Delta-\alpha\right\}
$$

This allows us to determine just the return to the relation-specific investment. This is given by:

$$
U^{S}(i)=\rho\left(v\left(q^{*}\right)+u^{s}\left(i^{*}\right)\right)\left(u^{s}(i) \Delta+\delta U^{S}(i)\right)
$$

In order to compute the return to an investment the key ingredients are the probability of staying matched and the flow returns from the investment. This is used to compute the expected payoff from a specific investment which implies:

Proposition 4. If it is optimal for the worker to invest a positive amount, then the optimal level of specific investment by the worker is uniquely defined by:

$$
d u^{s}\left(i^{*}\right) / d i=\left(1-\delta \rho\left(v\left(q^{*}\right)+u^{s}\left(i^{*}\right)\right) \delta\right) / \Delta
$$

Notice that increasing $i$ also increases the probability of the match continuing, but this does not add an extra first order term. The reason is that since matching is optimal, then at the margin the payoff from staying is equal to the payoff from 
leaving, and hence the first order effect of a change of $i$ on the probability is zero. This will not be the case when we come to the employment contract. We are now finally able to state the conditions for an optimal match.

Proposition 5. If $S^{*}\left(v\left(q^{*}\right)+u^{s}\left(i^{*}\right)\right) \geq i^{*}+I$ then it is efficient for the firm to hire the worker in period 0 . The optimal contract entails the worker selecting investment $i^{*}$ and attention/effort $q^{*}$. Employment continues until:

$$
v_{t}-u_{t}<\delta\left(\bar{u} / r-S^{*}\left(v\left(q^{*}\right)+u^{s}\left(i^{*}\right)\right) / \Delta-v\left(q^{*}\right)-u^{s}\left(i^{*}\right)\right.
$$

Separation eventually occurs with probability one.

This proposition follows directly from the definition of the surplus from the match. Separation eventually occurs because the distributions of the inside options are bounded below and unbounded above (they are log normal), hence regardless of the value of the surplus, one has $\rho\left(v\left(q^{*}\right)+u^{s}\left(i^{*}\right)\right)<1$. The optimum illustrates the idea that all relationships need to take into account the possibility of separation. The level of investment into a relationship is a decreasing function of the probability of separation.

Notice as well that as the length of a period falls, then the $S^{*} / \Delta$ term in expression 18 increases without bound. This implies that in this model with i.i.d. shocks, if the shocks are short lived, then once a relationship starts, the duration of the relationship is longer. Essentially, any individual shock is of less importance, and hence the relationship becomes more durable. In terms of transaction costs economics, a large $\Delta$ implies a lumpy, or large transaction that has a lower probability of continuing after parties have completed the first period. 


\section{Notes}

${ }^{1}$ See Lazear and Oyer (2012) for an excellent review of this literature. Kanemoto and MacLeod (1992) show that variations in worker characteristics can provide an explanation for the use of performance pay that fits in nicely with Gibbons (1987)'s work on when performance pay cannot be used. The issue of performance pay has its roots in the work of Taylor (1911). There is a large literature is psychology that explores the issue of incentives - much too vast to review here. Wickens (1992) provides a nice review. Also, Schmitt (1981) discusses how the previous literature on team incentives is psychology provides a pretty clear answer on how to design group incentives - much of the work having been completed before economists addressed the issue.

${ }^{2}$ See discussion on page 551.

${ }^{3}$ In our previous work, MacLeod and Parent (1999), we used the older Quality of Work Survey. Note also that strictly speaking, our data only contains information on bonuses. We assume that, like Brown's merit pay category, they are based on subjective evaluations of performance.

${ }^{4}$ Previous empirical work on transaction cost economics has focused upon industrial organization implications. See Tadelis and Williamson (2012) for a comprehensive review of the theory and Lafontaine and Slade (2012) for a discussion of the empirical evidence.

${ }^{5}$ Williamson (1981), page 563.

${ }^{6}$ This follows from the requirement that $\left(v_{t}-\gamma_{b}\left(q^{*}\left(U^{*}\right)\right) L-w\right) \Delta+\delta \Pi^{*}-\delta \gamma_{b}(q) \Delta I \geq$ 0 and $\left(\left(w-c\left(q^{*}\left(U^{*}\right)\right)+u^{s}(i)\right) \Delta+\delta\left(\left(1-\gamma_{b}\left(q^{*}\left(U^{*}\right)\right) \Delta\right) U^{*}+\gamma_{b}\left(q^{*}\left(U^{*}\right)\right) \Delta \bar{U}\right)\right) \geq$ $\left(u_{t} \Delta+\delta \bar{U}\right)$.

${ }^{7}$ We are grateful to David Autor for providing us with the DOT data and the 
supporting documentation.

${ }^{8}$ In the PSID, data on hours worked during year $t$, as well as on total labor earnings, bonuses/commissions/overtime income, and overtime hours, are asked in interview year $t+1$. Thus we actually use data covering interview years 1976-2005. Annual earnings were top coded at \$99,999 until 1982 (and not top coded since then), but only a handful of individuals were at the top code.

${ }^{9}$ Choosing another arbitrary cutoff year (say, 1991) did not make a substantive difference.

${ }^{10}$ Note that the question refers specifically to any amounts earned from bonuses, overtime, or commissions in addition to wages and salaries earned.

${ }^{11}$ Note that a subset of workers are observed in both non-contingent and contingent pay jobs.

${ }^{12}$ See Mellow and Sider (1983) for evidence that 3-digit occupations are riddled with measurement error in survey data.

${ }^{13}$ Of course, it would kill all the effects if we included 3-digit occupational dummies since those would absorb all the variation in the DOT characteristics.

${ }^{14}$ We also modeled unobserved heterogeneity using the non-parametric methodology proposed in Heckman and Singer (1984). The results were qualitatively identical.

\section{References}

Abreu, D., P. Milgrom, and D. Pearce (1991, November). Information and timing in repeated partnerships. Econometrica 59(6), 1713-1734.

Autor, D. H., F. Levy, and R. J. Murnane (2003, Nov). The skill content of recent technological change: An empirical exploration. Quarterly Journal of Economics 118(4), 1279-1333. 
Brown, C. (1990). Firm's choice of method of pay. Industrial and Labour Relations Review 43(3, Special Issue), 165S-182S.

Brown, C. (1992, Autumn). Wage levels and methods of pay. RAND Journal of Economics 23(3), 366-375.

Bull, C. (1987). The existence of self-enforcing implicit contracts. Quarterly Journal of Economics 102, 147-159.

Gibbons, R. (1987, October). Piece rate incentive schemes. Journal of Labor Economics 5, 413-29.

Grossman, S. J. and O. D. Hart (1981). Implicit contracts, moral hazard,unemployment. American Economic Review 71(2), 301-307.

Hall, R. E. and E. P. Lazear (1984, April). The excess sensitivity of layoffs and quits to demand. Journal of Labor Economics 2(2), 233-257.

Hashimoto, M. (1981, June). Firm specific capital as a shared investment. American Economic Review 71(3), 475-482.

Heckman, J. J. and B. Singer (1984, March). A method for minimizing the impact of distributional assumptions in econometric models for duration data. Econometrica 52, 271-320.

Holmes, O. W. (1897, Mar. 25). The path of the law. Harvard Law Review 10(8), $457-478$.

Holmström, B. (1979). Moral hazard and observability. Bell Journal of Economics 10(1), 74-91. 
Holmström, B. and P. Milgrom (1991). Multi-task principal-agent analyses: Incentive contracts, asset ownership, and job design. Journal of Law, Economics, and Organization 7, 24-52.

Jenkins, S. P. (1995, Feb). Easy estimation methods for discrete-time duration models. Oxford Bulletin of Economics and Statistics 57(1), 129-138.

Jovanovic, B. (1979). Job matching and the theory of turnover. Journal of Political Economy 87, 972-90.

Kanemoto, Y. and W. B. MacLeod (1992). The ratchet effect and the market for second hand workers. Journal of Labor Economics 10, 85-92.

Lafontaine, F. and M. Slade (2012). Inter-firm contracts. In R. Gibbons and J. Roberts (Eds.), Handbook of Organizational Economics. Princeton University Press.

Lazear, E. P. (1986). Salaries and piece rates. Journal of Business 59, 405-431.

Lazear, E. P. (2000, Dec). Performance pay and productivity. American Economic Review $90(5)$, 1346-1361.

Lazear, E. P. and P. Oyer (2012). Personnel economics. In R. Gibbons and J. Roberts (Eds.), Handbook of Organizational Economics, Chapter 12, pp. 479-519. Princeton, NJ: Princeton University Press.

Lemieux, T., W. B. MacLeod, and D. Parent (2009, February). Performance pay and wage inequality. Quarterly Journal of Economics 124(1), 1-49.

Lemieux, T., W. B. MacLeod, and D. Parent (2012, May). Contract form, wage flexibility and employment. American Economic Review $101(3)$. 
MacLeod, W. B. (2007, September). Reputations, relationships and contract enforcement. Journal of Economics Literature XLV, 597-630.

MacLeod, W. B. and J. M. Malcomson (1989, March). Implicit contracts, incentive compatibility, and involuntary unemployment. Econometrica 57(2), 447-480.

MacLeod, W. B. and D. Parent (1999). Job characteristics and the form of compensation. Research in Labor Economics 18, 177-242.

Mellow, W. and H. Sider (1983). Accuracy of response in labor market surveys: Evidence and implications. Journal of Labor Economics 1, 331-344.

Meyer, B. (1990, July). Unemployment insurance and unemployment spells. Econometrica $58,757-782$.

Oyer, P. (2004, Aug). Why do firms use incentives that have no incentive effects? Journal of Finance 59(4), 1619-1649.

Ross, S. (1973). Economic theory of agency: the principal's problem. American Economic Review 63, 134-39.

Schmitt, D. R. (1981). Performance under cooperation or competition. American Behavioral Scientist 24(5), 649-679.

Shapiro, C. and J. E. Stiglitz (1984, June). Equilibrium unemployment as a worker discipline device. American Economic Review 74 (3), 433-444.

Tadelis, S. and O. Williamson (2012). Transactions costs economics. In R. Gibbons and J. Roberts (Eds.), Handbook of Organizational Economics. Princeton University Press. 
Taylor, F. W. (1911). The principles of scientific management. New York ; London: Harper. by Frederick Winslow Taylor ... $23 \mathrm{~cm}$.

Weitzman, M. L. (1985). The simple macroeconomics of profit sharing. The American Economic Review 75(5), pp. 937-953.

Wickens, C. (1992). Engineering Psychology and Human Performance. New York, N.Y.: HarperCollins Publishers Inc.

Williamson, O. E. (1981). The economics of organization: The transaction cost approach. American Journal of Sociology 87(3), pp. 548-577.

Williamson, O. E., M. L. Wachter, and J. E. Harris (1975, Spring). Understanding the employment relation: the analysis of idiosyncratic exchange. Bell Journal of Economics 6(1), 250-278. 


\section{B Tables}

Table 1. Task Content Measures in the Dictionary of Occupational Titles 1977 4th Edition and 1991 Revision

DOT Variable Interpretation

Routine Manual

Routine Cognitive

Non-routine Manual

Non-routine Cognitive-Analytical

$$
\text { of }
$$
subtract to being able to perform complex mathematically-oriented analysis.

Non-routine Cognitive-Interactive Measures interactive, communication, planning, and managerial skills, as well as ability to process and synthesize information. 


\begin{tabular}{|c|c|c|}
\hline & $\begin{array}{c}\text { Non-Contingent } \\
\text { Pay Jobs }\end{array}$ & $\begin{array}{l}\text { Contingent } \\
\text { Pay Jobs }\end{array}$ \\
\hline Routine manual & 0.06 & -0.24 \\
\hline Non-routine manual & 0.15 & -0.49 \\
\hline Routine cognitive & 0.09 & -0.19 \\
\hline Non-routine cognitive/interactive & -0.28 & 0.83 \\
\hline Non-routine cognitive/analytical & -0.18 & 0.55 \\
\hline Average Hourly Earnings (\$79) & 7.94 & 11.98 \\
\hline Education & 12.30 & 14.32 \\
\hline Potential Experience & 20.16 & 20.92 \\
\hline Employer Tenure & 7.52 & 9.30 \\
\hline Married & 0.71 & 0.78 \\
\hline Unionized & 0.30 & 0.04 \\
\hline Non White & 0.15 & 0.07 \\
\hline Fraction Unemployed at Interview & 0.068 & 0.008 \\
\hline Annual Hours Worked & 2076.3 & 2263.7 \\
\hline \# workers (Tot:3090) & 2590 & 1289 \\
\hline \# Job Matches (Tot: 8911) & 6780 & 2131 \\
\hline \# Observations (Tot: 28415) & 19650 & 8765 \\
\hline
\end{tabular}

Notes: The sample consists of male household heads aged 18-64 working in private sector, wage and salary jobs. All figures in the table represent sample means.

Education, potential experience, and employer tenure are measured in years.

Potential experience is defined as age minus education minus 6. See text for the definition of a non-contingent pay job. All Dictionary of Occupational Titles task content variables are standardized with mean zero and unit variance. Temporarily laid off workers are included among the unemployed. 


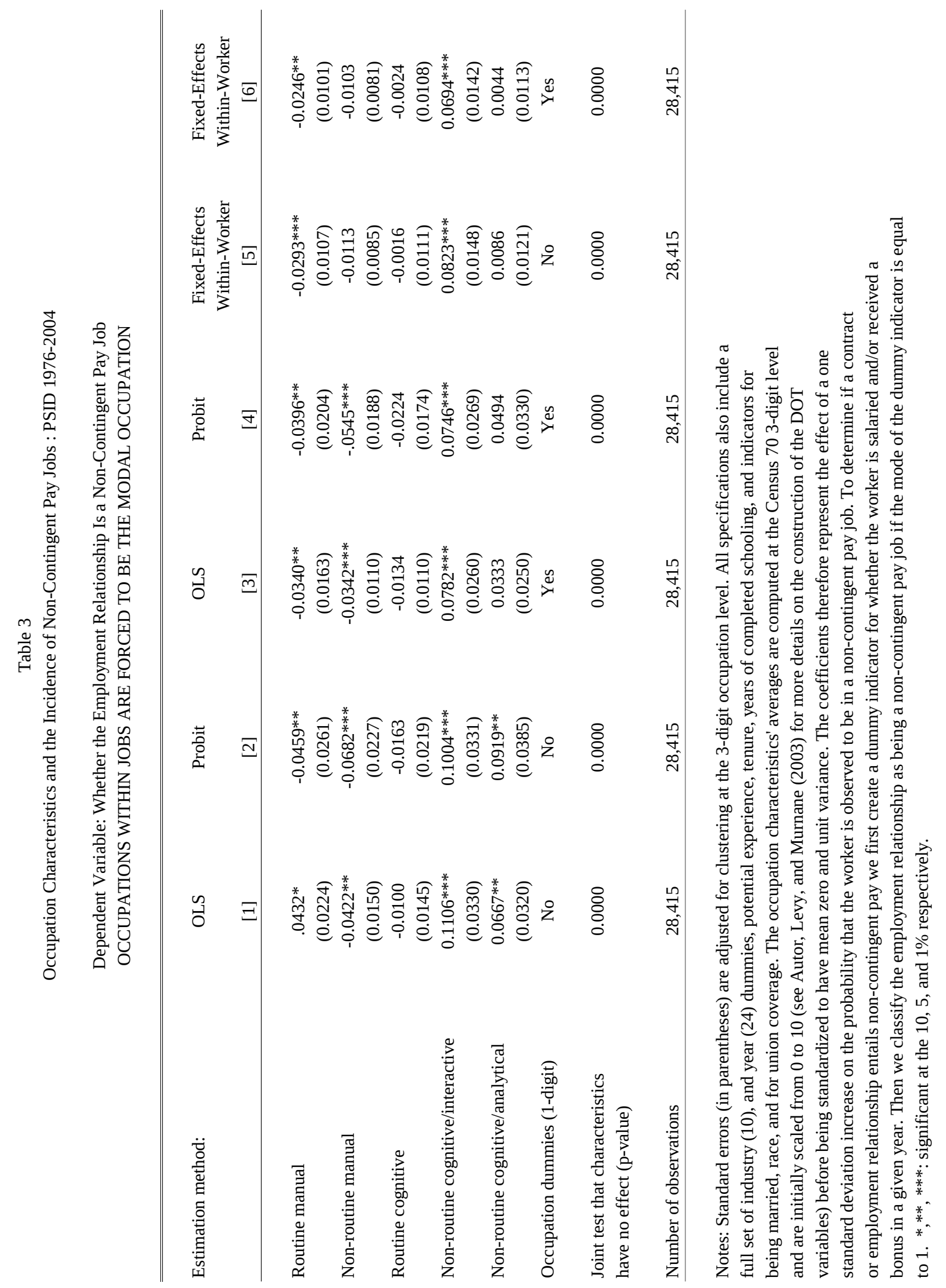




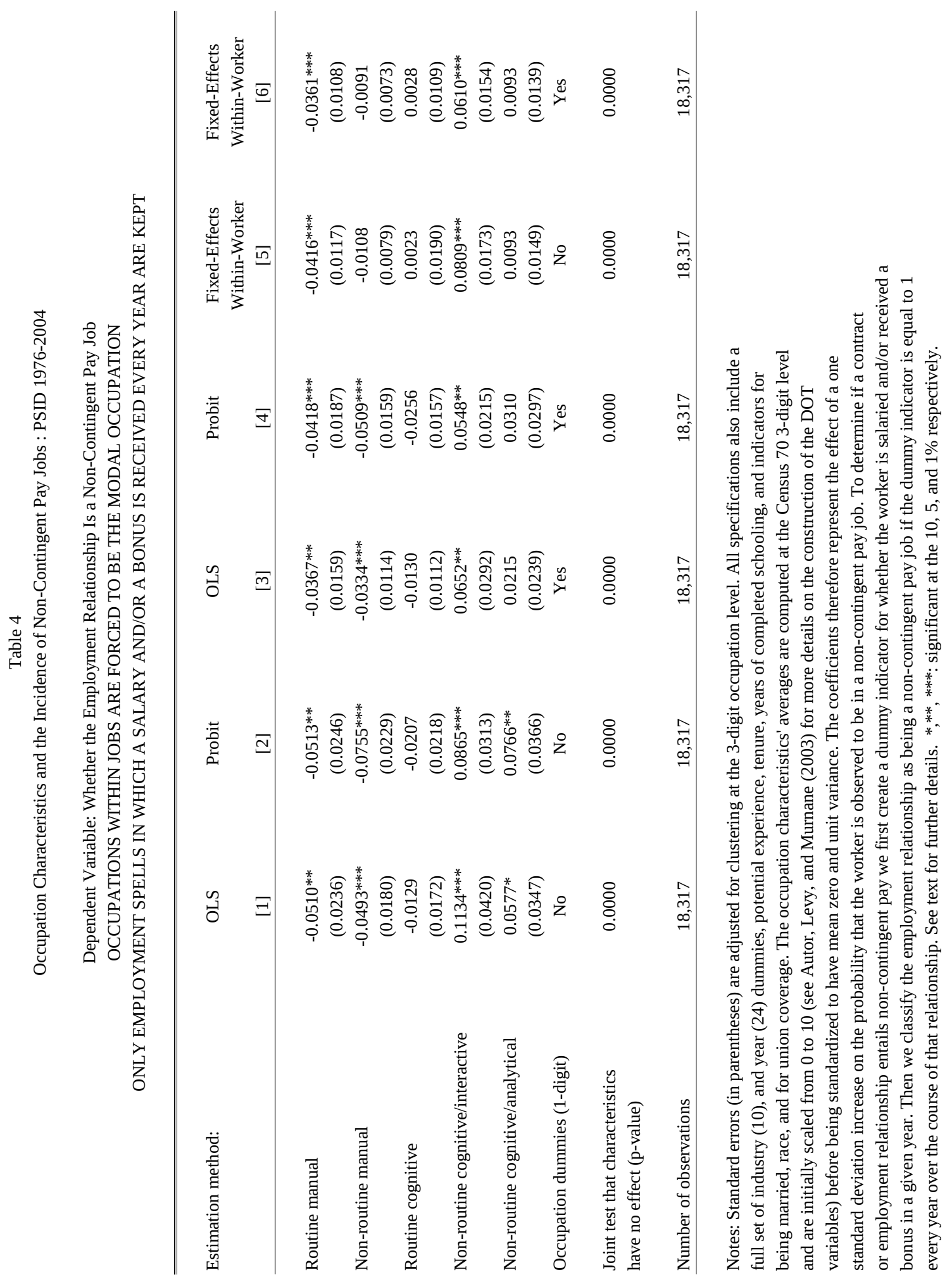




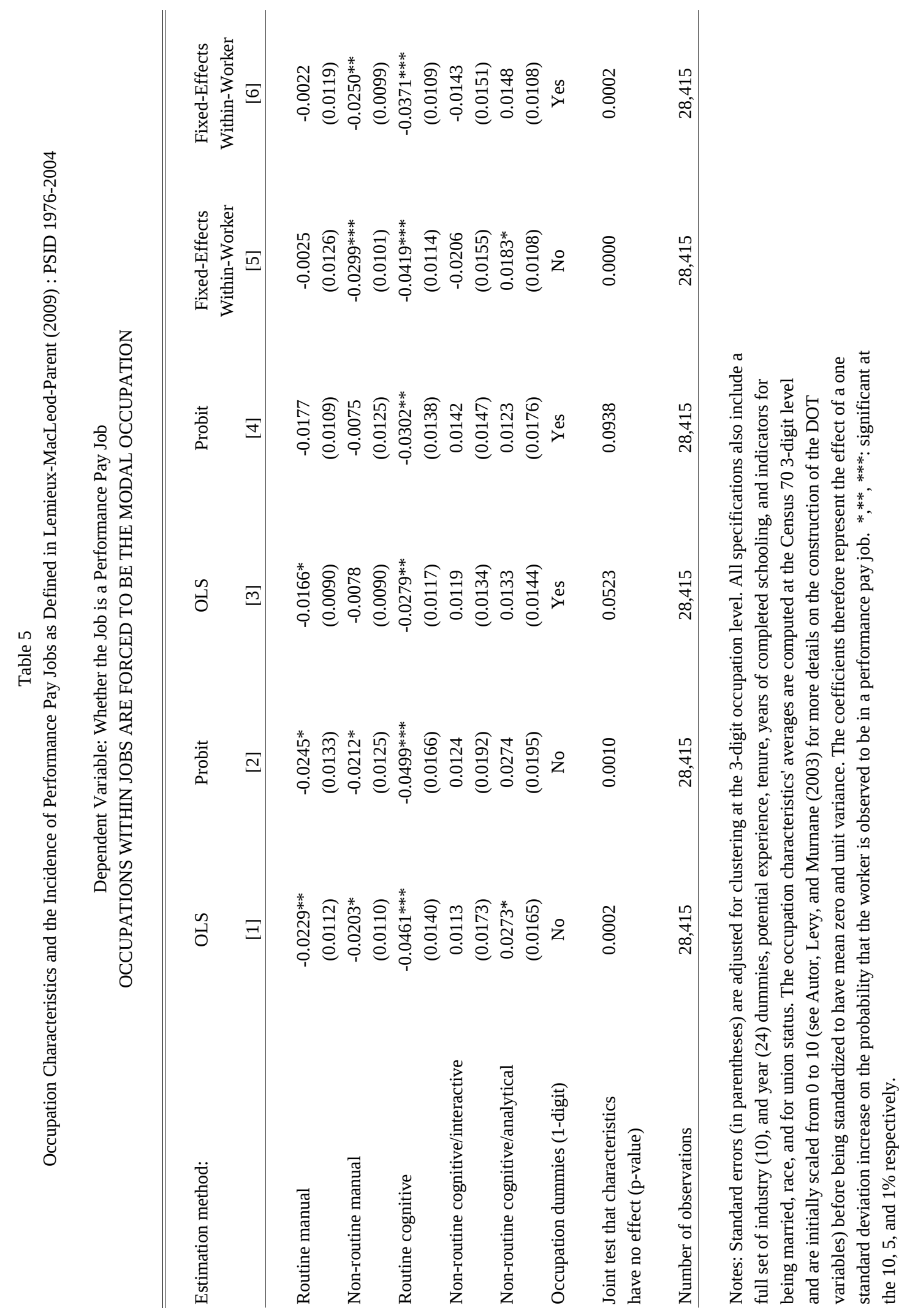


Table 6

Regression Estimates of the Effect of Being in a Non-Contingent Pay Job on Log Average Hourly Earnings

\begin{tabular}{|c|c|c|c|c|}
\hline \multirow[t]{2}{*}{ Estimation method: } & \multicolumn{2}{|c|}{ OLS } & \multicolumn{2}{|c|}{ Fixed effects } \\
\hline & [1] & [2] & [3] & [4] \\
\hline Non-contingent pay Job & $\begin{array}{c}0.1130 * * * \\
(0.0188)\end{array}$ & $\begin{array}{c}0.1095^{* * *} \\
(0.0193)\end{array}$ & $\begin{array}{c}0.0363^{* * *} \\
(0.0084)\end{array}$ & $\begin{array}{c}0.0364 * * * \\
(0.0085)\end{array}$ \\
\hline Routine manual & - & $\begin{array}{c}0.0089 \\
(0.0082)\end{array}$ & - & $\begin{array}{c}0.0093 * * * \\
(0.0036)\end{array}$ \\
\hline Non-routine manual & - & $\begin{array}{c}0.0194 \\
(0.0100)\end{array}$ & - & $\begin{array}{c}0.0114^{* * *} \\
(0.0042)\end{array}$ \\
\hline Routine cognitive & - & $\begin{array}{c}0.0040 \\
(0.0087)\end{array}$ & - & $\begin{array}{c}-0.0079 * * \\
(0.0037)\end{array}$ \\
\hline Non-routine cognitive/interactive & - & $\begin{array}{c}0.0118 \\
(0.0115)\end{array}$ & - & $\begin{array}{c}0.0026 \\
(0.0047)\end{array}$ \\
\hline Non-routine cognitive/analytical & - & $\begin{array}{c}0.0429 * * * \\
(0.0105)\end{array}$ & - & $\begin{array}{c}0.0262 * * * \\
(0.0085)\end{array}$ \\
\hline Worker fixed effect & No & No & Yes & Yes \\
\hline
\end{tabular}

Notes. 28,415 observations. Standard errors (in parentheses) are adjusted for clustering at the worker level level. All specifications also include a full set of industry (10), occupations (8), and year (22) dummies, a cubic in potential experience, a quadratic in job tenure, years of completed schooling, and dummies for being married, nonwhite, and for union status. To determine if a contract or employment relationship involves non-contingent pay we first create a dummy indicator for whether the worker is salaried and/or received a bonus in a given year. Then we classify the employment relationship as being a non-contingent pay job if the mode of the dummy indicator is 1 over the course of that relationship. See text for further details. ${ }^{* * *}, * * *$ : significant at the 10,5 , and $1 \%$ respectively. 


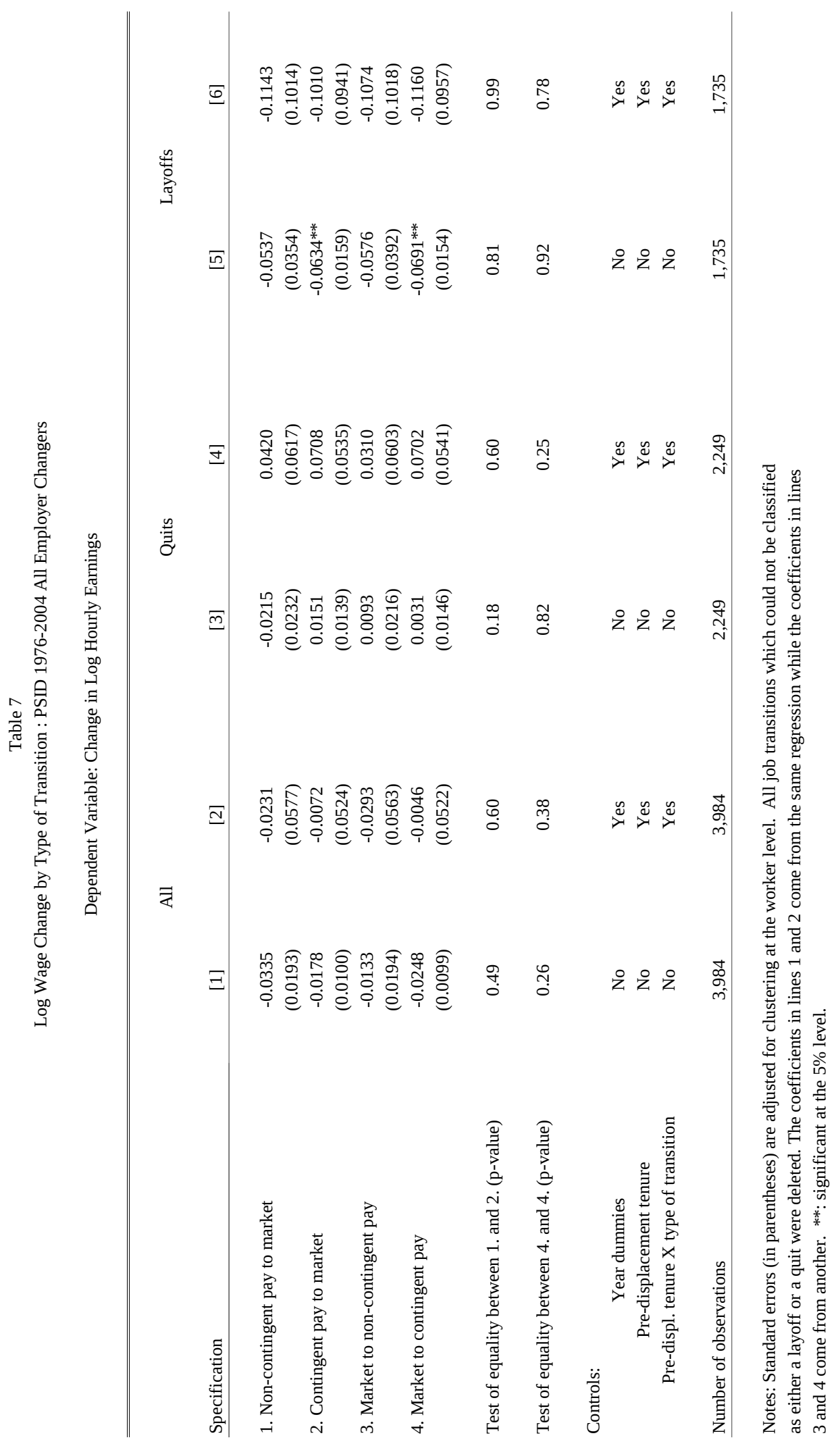


Table 8. Grouped-Data Hazard Model Estimates

\begin{tabular}{|c|c|c|c|c|}
\hline \multirow{2}{*}{$\begin{array}{l}\text { Variable } \\
\text { Non-contingent pay job }\end{array}$} & \multicolumn{2}{|c|}{ Without Control for Heterogeneity } & \multicolumn{2}{|c|}{ With Control for Heterogeneity } \\
\hline & $\begin{array}{c}0.777 * * * \\
(0.024)\end{array}$ & $\begin{array}{l}.862 * * \\
(0.058)\end{array}$ & $\begin{array}{c}0.750^{* * *} \\
(0.029)\end{array}$ & $\begin{array}{l}.851^{* *} \\
(0.068)\end{array}$ \\
\hline $\begin{array}{l}\text { Unemployment rate } \\
\text { in county of residence }\end{array}$ & - & $\begin{array}{c}1.016^{* * *} \\
(0.005)\end{array}$ & - & $\begin{array}{l}1.02 * * * \\
(0.006)\end{array}$ \\
\hline Unemp. rate $\mathrm{X}$ non-contingent pay job & & $\begin{array}{l}0.984^{*} \\
(0.009)\end{array}$ & & $\begin{array}{l}0.980^{*} \\
(0.011)\end{array}$ \\
\hline Potential experience & $\begin{array}{c}0.989 \\
(0.008)\end{array}$ & $\begin{array}{c}0.988 \\
(0.008)\end{array}$ & $\begin{array}{c}0.994 \\
(0.010)\end{array}$ & $\begin{array}{c}0.995 \\
(0.010)\end{array}$ \\
\hline Education & $\begin{array}{l}1.008 \\
(0.006)\end{array}$ & $\begin{array}{l}1.008 \\
(0.006)\end{array}$ & $\begin{array}{l}1.007 \\
(0.008)\end{array}$ & $\begin{array}{l}1.008 \\
(0.008)\end{array}$ \\
\hline Covered by CBA & $\begin{array}{c}0.644^{* * *} \\
(0.022)\end{array}$ & $\begin{array}{c}0.642^{* * * *} \\
(0.022)\end{array}$ & $\begin{array}{c}0.599 * * * \\
(0.025)\end{array}$ & $\begin{array}{c}0.599 * * * \\
(0.025)\end{array}$ \\
\hline Married & $\begin{array}{c}0.740^{* * * *} \\
(0.018)\end{array}$ & $\begin{array}{c}0.739 * * * \\
(0.018)\end{array}$ & $\begin{array}{c}0.728^{* * *} \\
(0.021)\end{array}$ & $\begin{array}{c}0.726^{* * *} \\
(0.021)\end{array}$ \\
\hline Nonwhite & $\begin{array}{l}1.053^{* *} \\
(0.027)\end{array}$ & $\begin{array}{l}1.050^{*} \\
(0.027)\end{array}$ & $\begin{array}{l}1.059 * * \\
(0.034)\end{array}$ & $\begin{array}{l}1.062 * \\
(0.034)\end{array}$ \\
\hline Industry dummies & Yes & Yes & Yes & Yes \\
\hline Occupation dummies & Yes & Yes & Yes & Yes \\
\hline Year dummies & Yes & Yes & Yes & Yes \\
\hline $\begin{array}{l}\text { - Log likelihood } \\
\text { LR test of zero gamma variance } \\
\text { [p-value] }\end{array}$ & $\begin{array}{c}14961.2 \\
-\end{array}$ & $\begin{array}{c}14956.5 \\
-\end{array}$ & $\begin{array}{c}14822.0 \\
278.3 \\
{[0.0000]}\end{array}$ & $\begin{array}{c}14812.7 \\
287.6 \\
{[0.0000]}\end{array}$ \\
\hline $\begin{array}{l}\text { Number of job matches: } 8911 \\
\text { Number of interval-specific obs.: } 28415\end{array}$ & & & & \\
\hline
\end{tabular}

The parameter estimates are the exponentiated coefficients and thus represent the hazard ratio. *, **, ***: significant at the 10,5 and $1 \%$ level, respectively. Worker heterogeneity is modelled using a gamma distribution function while the baseline hazard is estimated as being piece-wise constant using interval-specific dummy variables (9 intervals). 